\title{
Temor e poder em Harold Pinter The room: uma microfísica do medo
}

Carlos Cardoso Martins MOREIRA ${ }^{1}$ Universidade Federal do Estado do Rio de Janeiro - UNIRIO

Em Alteridad y alienación sexual en la dramaturgia de Harold Pinter, Ignácio Ramos Gay observa que "curiosamente [e] apesar de que suas declarações públicas anti-belicistas [...] e sua trajetória biográfica ${ }^{2}[. .$.$] aparentemente contradigam essa postura de pacifismo radical$ supostamente alheio a um engajamento político", esse autor britânico, que começa a produzir no final da década de 1950, "sempre se declarou apolítico em sua recriação teatral" (GAY, 2006, p. 66).

Ainda em Alteridady alienación..., Ramos Gay expõe a tese de que, "sabedor do risco de confinar seu teatro a um contexto historicista", o objetivo de Pinter não seria "remeter a um conflito social determinado [...] mas, sim, transcender a limitação temporal para captar os personagens em sua essência, numa tentativa de definir as formas de subjugação despojando-as de seu revestimento acidental” (Idem, p. 68).

Para Gay, o confinamento das personagens de Pinter no "espaço obsessivo da habitação", tornaria possível operar uma "transcrição microscópica, por meio da linguagem, das transformações nas relações entre os sujeitos" (Idem, p.67).

Em The room, primeira peça de Harold Pinter, estreada em 1957, o casal dos Hudd, Bert e Rose, é locatário de um pequeno apartamento em uma casa de geografia imprecisa e lacunar.

No longo solilóquio com que abre o drama, e durante o qual prepara e serve uma refeição para Bert, Rose define as qualidades do espaço que ela e o marido habitam. Define também a si própria. Mas, sobretudo, e sem que este durante toda a cena emita um som sequer, define Bert.

Francis Gillen, em Humanismo e vitalidade nas peças de Harold Pinter, destaca o modo como este, a seu ver, "chama a atenção para a natureza política da linguagem, para o silêncio como forma de desacordo, para o fracasso na transmissão de sentido na maior parte dos exercícios de conversação" (GILLEN, 2008, p. 55).

\footnotetext{
${ }^{1}$ Artista pesquisador; dramaturgo, encenador, diretor musical, cenógrafo. Fundador e diretor artístico do Era uma galera, coletivo que se reúne pela primeira vez em 2003 para levar à cena Um soldadinho de chumbo, primeiro dos quatro textos de Cardoso encenados pelo grupo, com direção do autor.

${ }^{2}$ Por se recusar a prestar o serviço militar, alegando objeção de consciência, Pinter quase foi preso. 
O silêncio de Bert na cena inicial de The Room poderia denotar desacordo, bem como, no entanto, assentimento tácito, ou ambas as coisas... Ou ainda desagrado com a loquacidade invasiva da mulher, que o comenta e define. (Das três, parece mais atraente a última hipótese, que teria inclusive o poder de acolher, e congregar, quaisquer outras). De todo modo, para concordar ou discordar, desagradar-se ou não, seria preciso que Bert conferisse às falas de Rose algum sentido. E elas, aliás, já por si comportam significados muito precisos; determinações do que Bert pode fazer e ser:

Rose - Já olhaste lá para fora hoje? Há gelo na rua. Oh, eu sei que és capaz de conduzir. Não digo que não sejas capaz de conduzir. Esta manhã contei ao Sr. Kidd que ias sair hoje. Disse-lhe que não tens andado muito em forma, mas disse, ainda assim, ele é um condutor fantástico. Que eu não me importava as horas, onde, nada, Bert. Tu sabes conduzir. Disse-lhe.

Ou, ainda:

Rose - Este é um bom quarto. Num sítio assim temos hipóteses. Eu tomo conta de ti, não tomo, Bert? Como quando nos ofereceram a cave e eu disse logo que não. Eu sabia que não ia servir. O teto mesmo por cima de ti. Não, aqui tens uma janela, podes mexer-te, podes voltar para casa à noite, se tiveres de sair, podes fazer o teu trabalho, podes voltar para casa, estás bem. E eu estou aqui. Tens hipóteses.

Manuel F. Vieites relembra uma entrevista em que Pinter diz que é "para além desses atributos (os atributos evidentes de expressão, dos personagens e de nós mesmos) que uma linguagem surge. Uma linguagem onde, sob o que é dito, outra coisa está sendo dita" (VIEITES, 2006, p. 55).

O verbo dizer domina o primeiro desses dois trechos da fala inicial de Rose em The Room. Nele, depois de definir Bert como "um condutor" que "sabe conduzir", Rose conclui seu veredito com um solenemente isolado, afirmativo e enfático "Disse-lhe". É o que importa: o que se diz. O que Rose diz sobre Bert, a ele próprio e ao mundo, é o que Bert é e pode ser.

No segundo segmento, a mulher descreve as hipóteses de deslocamento do marido. Bert pode sair, pode voltar... Define o companheiro no espaço da habitação e do mundo, mas, principalmente, restringe-lhe a imaginação, impondo-lhe, desde já, como por precaução, uma limitação que é a própria presença da limitadora. Ela mesma, Rose: "E eu estou aqui. Tens hipóteses". 
Sobre os discursos da verdade, Michel de Foucault faz, em Soberania e disciplina, a seguinte reflexão: "Por outro lado, estamos subjugados à verdade também no sentido em que ela é lei e produz o discurso verdadeiro que decide, transmite e reproduz, ao menos em parte, efeitos de poder" (FOUCAULT, 2008, p. 180).

No mundo que o discurso de Rose cria e recria para ela e para Bert, o que não há são hipóteses. As que lista para o marido são a mera descrição do conhecidíssimo cotidiano de ambos; o dia-a-dia que compartilham no espaço extremamente essencial do quarto, onde se enfrentam.

Foucault (2008, p. 184) prescreve que se analise "a maneira como os fenômenos, as técnicas e os procedimentos de poder atuam nos níveis mais baixos". Diz não crer que "o que se forma na base sejam ideologias", e afirma: "é muito menos e muito mais do que isso" (Idem, p. 186).

Os personagens de The room são apolíticos, não produzem ou fazem menção a ideologias que os definam a si e a suas circunstâncias, mas por seus discursos constroem um substitutivo do poder de definição e delimitação da ideologia: uma biografia. Tentam impor-se intenções, desejos, necessidades, suspeitas, restrições espaciais, etc. Suas palavras ocupam os espaços vazios do discurso do interlocutor e os colonizam, substituindo por uma nova a biografia antes vigente.

Se, para Foucault (2008, p. 183-4), “o indivíduo não é o outro do poder [mas] um de seus primeiros efeitos [e] pelo próprio fato de ser um efeito, é seu centro de transmissão", passando, o poder, "através do indivíduo que ele constitui”, para Harold Pinter a própria alteridade é o poder. Ramos Gay (2006, p. 68) observa que no universo pinteriano o individuo "não adquire sua identidade senão a partir dessa alteridade que o oprime". E se,

efetivamente, aquilo que faz com que um corpo, gestos, discursos e desejos sejam identificados e constituídos enquanto indivíduos é um dos primeiros efeitos do poder, [...] poder [que] deve ser analisado como algo que circula [...] que só funciona em cadeia. Nunca [...] localizado aqui ou ali, nunca [...] nas mãos de alguns, nunca [...] apropriado como uma riqueza ou um bem [...] Na sua malha os indivíduos não só circulando, mas estando sempre em posição de exercer este poder e de sofrer sua ação, (FOUCAULT, 2008, pp.183-4)

em Pinter, onde esse poder se funda na alteridade, na existência do outro, a sua natureza movediça se reflete na quase impossibilidade de determinar a quem pertence, quem o detém plenamente; quem venceu o confronto ou obteve cabal triunfo sobre o oponente... 
Na primeira cena de The room o silêncio de Bert pode, de fato, ser percebido como sinal de derrota, de submissão a Rose. No entanto, em uma de suas falas Rose diz a Bert ter afirmado para o senhorio, Sr. Kidd, que ele, Bert, é um ótimo condutor. Esse elogio não é uma aventura de Rose; sobre ele estão ambos assentes. Produziram-no de comum acordo. No fim da peça, Bert o reiterará.

Foucault (2008, p. 180) nota que em nossa sociedade "somos submetidos pelo poder à produção da verdade e só podemos exercê-lo através da produção da verdade". Pinter não discute absolutamente se o que seus personagens dizem de si mesmos e sobre os outros é verdade ou não. De resto, verdade onde, se mal se referem ao que é geral, e mesmo quando o fazem estão se referindo também ao particular de si ou do outro, que é o que os ocupa e preocupa, e não ao mundo, como objeto a ser exposto, comentado e analisado? Onde verificar a verdade do que é afirmado, se tudo se dá praticamente em segredo, como que entre iniciados?

Em Pinter, o validador dos discursos de poder produzidos pelos indivíduos é, necessariamente, o outro: aquele que se quer afetar diretamente. E se este se conformará, e como, a essa verdade que lhe é imposta, isto dependerá apenas das posições de força dos jogadores envolvidos no lance.

$\mathrm{Na}$ última cena Bert retornará e encontrará a mulher com outro homem na habitação. Começará então a falar. Mas seu discurso não definirá ou delimitará Rose, e sim, antes de tudo, a si próprio, a quem, ao descrever como guiou com firmeza o automóvel pela noite escura e fria, trazendo-o de volta à casa, estará identificando ao condutor de que falara Rose:

Bert - Voltei sim senhor.

Rose (Dirigindo-se a ele) - Sim.

Bert - Voltei sim senhor

Pausa

Rose - É tarde?

Bert - Dei uma bela voltinha.

Pausa

Guiei-a para lá, firme. Fizeram um escuro lá fora.

Rose - Sim.

Bert - Depois guiei-a de volta, firme. Fizeram um gelo lá fora.

Rose - Sim.

Bert - Mas, guiei-a.

Pausa

A fiz correr. 
O silêncio anterior de Bert denotaria, então - mais do que assentimento -, vitória, posse do poder; pois, aqui, o discurso de Rose se identificaria com o de Bert, condutor e líder legítimo do casal. Mas essas reduções supõem algum grau de estabilidade do poder. E isso é justamente o que Pinter problematiza. Afinal, se o poder reside na alteridade ela mesma, a única maneira de garantir uma posse segura e estável do poder seria a eliminação do outro. Posse absoluta, mas solitária. E isso os personagens de Pinter não querem. O que fazem é tentar conter, reduzir, domesticar a ameaça que o outro representa, desacreditando a sua biografia, desestabilizando-o, subtraindo-lhe território. Bert e Rose formam uma união longeva e, a seu modo, estável.

Em certa altura, Rose recebe a visita especular de um jovem casal, os Sands, interessado em um dos quartos da casa. O quarto número 7 , precisamente o que ela e Bert ocupam.

Do interior de sua habitação, o que Rose mais teme é ver surgir, lá fora, do escuro da noite, "alguém" cuja proximidade venha ameaçar o edifício do casal. Mantém sempre cerradas as cortinas da janela, e sobre os habitantes do porão da casa diz a Bert: "Nunca vi quem é"; e explicita: "Quem é que é". O que teriam o poder de ser, esses estranhos? Que hipóteses desestabilizadoras trariam consigo? E, no entanto, apesar de viver em angústia e sobressalto, à espera de uma irrupção que antevê, quando os Sands batem à sua porta Rose os convida a entrar para que se aqueçam ao calor do fogão. Não há incoerência; os personagens de Pinter querem segurança, não solidão. Essencialmente gregários, nada deve, no entanto, ultrapassar as fronteiras que garantem a frágil estabilidade a que se apegam: nem eu, nem o outro. Nessa perspectiva, seus discursos não são tanto mecanismos invasores, de franca e agressiva expansão das personalidades, quanto de contenção geral. Entre as individualidades expostas por Pinter em seus microcosmos o poder não se transfere; transmite-se, como uma corrente, por um excelente condutor: o medo, o temor.

Rose e Todd - o Sr. Sands - disputam o direito à posse do quarto numa espécie de jogo em que o objeto em disputa é velado e que consiste em dizer verdades sobre o outro e resistir a verdades ditas pelo outro. Ambos conhecem o jogo e a importância da mobilidade. Estático, o poder é morto. Rose oferece assento a Todd, próximo ao fogo, mas ele recusará secamente o convite. Também às instâncias da própria mulher reagirá da mesma forma. Permanecerá de pé, e no frio. Firme, alerta, pronto para dar sequência ao ataque que já iniciou. 
Poderíamos reconhecer no diálogo abaixo, em que o Sr. Sands submete Rose a um verdadeiro interrogatório sobre Kidd, o senhorio, um bom exemplo do que Gillen entende como "fracasso na transmissão do sentido" em Pinter, mas o que aí de fato se dá são as preliminares do jogo, muito bem conhecidas pelos jogadores. Apenas, sob o que se diz, outra coisa está sendo lida por eles.

Sr. Sands - Como foi que disse que se chamava?

Rose - Hudd.

Sr. Sands - Isso mesmo. Então é a mulher do tipo que mencionou?

Sra. Sands - Não, não. Esse era o Sr. Kidd.

Sr. Sands - Era? Pensei que fosse Hudd.

Sra. Sands - Não, foi Kidd. Não foi, Sra. Hudd?

Rose - Isso mesmo. O senhorio.

Sra. Sands - Não. O senhorio não. O outro homem.

Rose - Bom, é esse o nome. É ele o senhorio.

Sr. Sands - Quem?

Rose - O Sr. Kidd.

Pausa

Sr. Sands - É?

E, ainda sobre o senhorio, mais adiante:

Sr. Sands - Mas, ele vive cá, é?

Rose - Claro que vive cá.

Sr. Sands - E diz que é o senhorio, é?

Rose - Claro que é.

E prossegue,

Sr. Sands - Ele vive cá, é?

Rose - Sim, mas não sei...

Sr. Sands - Não sabe exatamente onde é que ele para?

Rose - Não, exatamente não.

Sr. Sands - Mas ele vive mesmo cá, não vive? 
Com o cacoete de um policial ou promotor de justiça, Todd põe sob suspeita os conhecimentos e a autobiografia que a Sra. Hudd apresentara ao casal. Pretende assim desautorizar suas pretensões a um maior direito a pertencer à casa, e ao quarto.

Rose já travara um duelo da cadeira, com o Sr. Kidd, ainda na primeira parte da peça, logo depois da longa fala inicial, quando o senhorio bate à porta dos Hudd.

Rose convida-o a sentar-se. Ele declina. E quando ela quer saber qual quarto da casa habita, a resposta que Kidd lhe dá é a afirmação soberana da sua total liberdade: "Eu posso escolher". Kidd tem poder de escolha. Seus limites não são abarcáveis pela visão e nem mesmo pela imaginação de Rose. É o dono da casa, mas não necessariamente de fato. Nada em Pinter poderia ser tão simplesmente "de fato". O que dá posse da casa a Kidd é ser, antes de mais nada, o seu biógrafo. Isso basta e é tudo. Kidd tem poder de escolha porque na equívoca geografia que descreve um tanto displicentemente para Rose pode sempre inventar para si um lugar que permanecerá incógnito para os outros.

Rose lhe pergunta quantos andares tem a casa. O senhorio responde:

Sr. Kidd - Oh, costumava contá-los em tempos. Nunca me cansava. Costumava ter tudo sob controle nesta casa. Havia muita coisa para ter debaixo de olho, nessa altura. Também estava apto para isso. Isso era enquanto minha irmã era viva. Mas depois dela morrer perdi um bocado o rumo.

Kidd está, então, naquela condição especial; a única em que é verdadeiramente possível garantir a posse seja do que for: Kidd é só. Sua estabilidade, porém, paga à solidão um tributo: não tendo quem o defina e delimite, Kidd torna-se vago e impreciso. Tem o controle, o domínio da própria imaginação, mas não tem muito o que fazer com ela. E mesmo esta já se vê afetar pela aparição de um estrangeiro: o Negro.

Quando os Sands tiverem saído, Kidd voltará para anunciar a Rose que há dias habita o porão um homem que diz conhecê-la e desejar vê-la. Pede-lhe que o receba, pois quer ver-se livre dessa presença que o oprime. Abalado pela independência de uma outra biografia, senhora de um outro lugar, um lugar exterior aos limites em que os seres que habitam a casa evoluem sob seu domínio e vigilância, o senhorio não é mais o mesmo.

Para alívio de Kidd, Rose, por fim, aceita receber o homem.

Ao entrar no apartamento, Riley se apresenta. Diz seu nome. Rose, não. Também os Sands nomearam-se um ao outro, mas não disseram, cada um, o seu próprio nome. Riley é o único personagem em The Room que diz seu próprio nome, que se autonomeia. 
Sua força está aí. A violência dessa autodefinição desestabiliza instantaneamente a senhora Hudd:

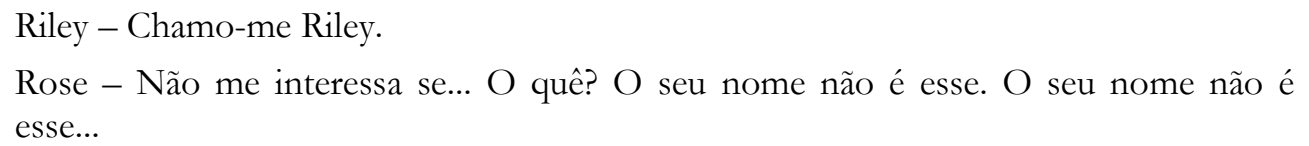

Riley se diz Riley e Rose não encontra, para opor a essa afirmação que tem diante de si, nada melhor do que dela dizer que é equívoca. É pouco.

O diálogo prossegue até ter início a metamorfose de Rose em Sal, que Bert, retornando, susta:

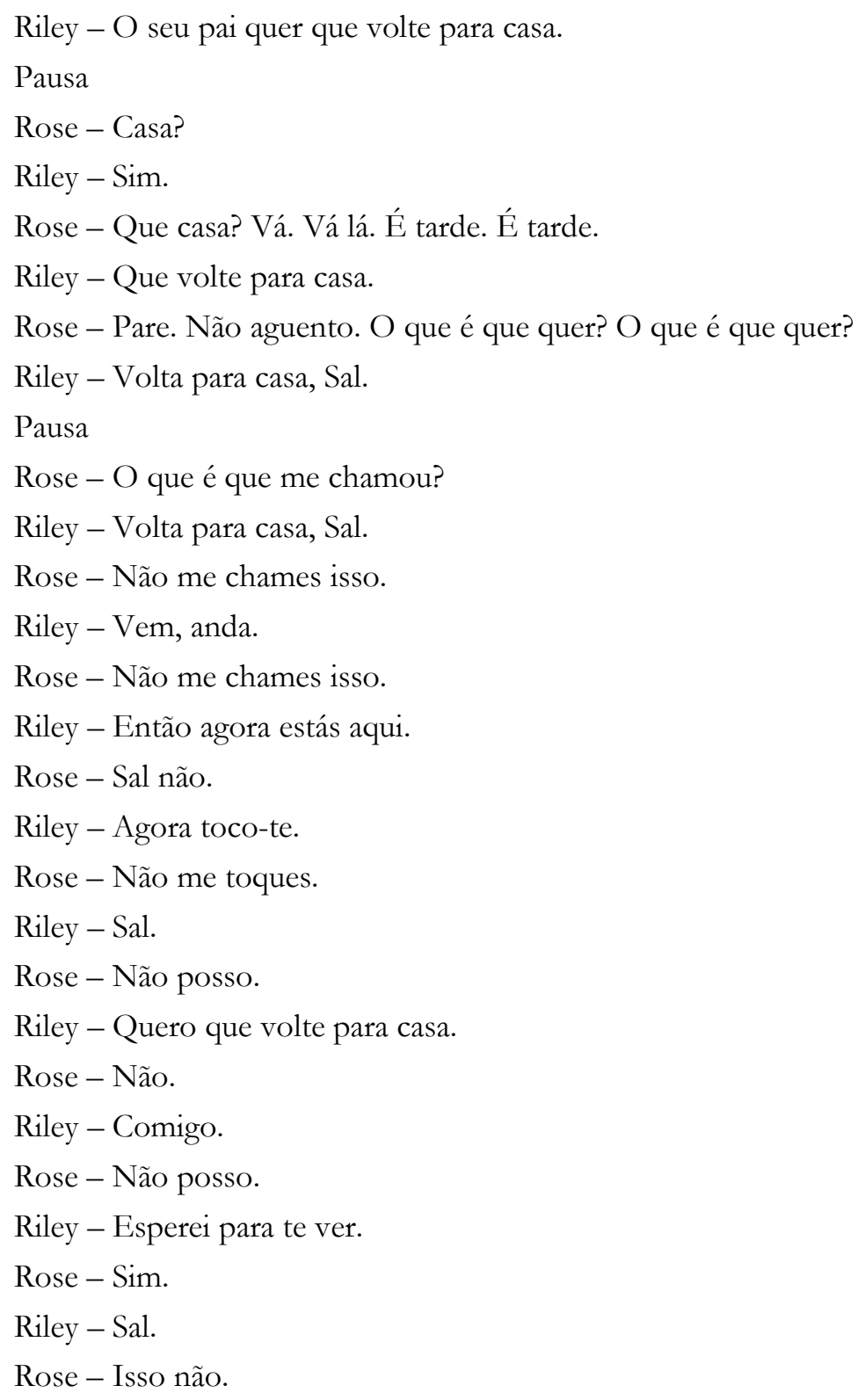




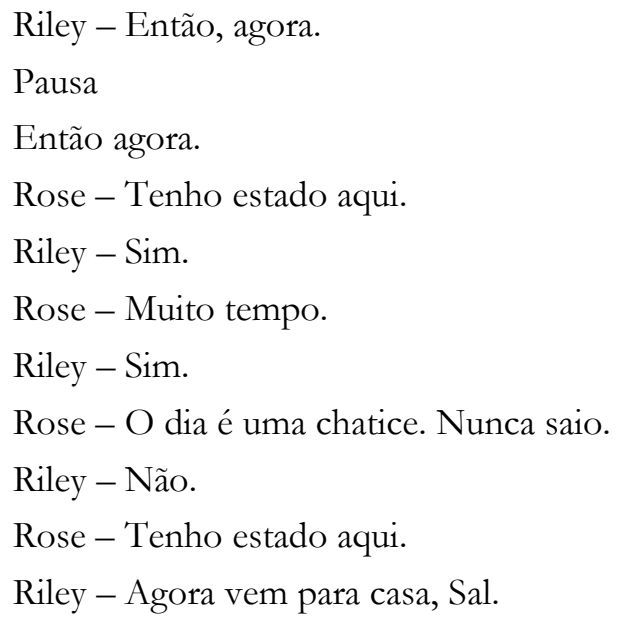

Ela toca nos olhos, na nuca e nas têmporas dele com as mãos. Bert entra.

Ramos Gay recorda uma entrevista em que Pinter afirmava que na juventude havia sido profundamente marcado pelas transmissões radiofônicas e projeções cinematográficas de resumos dos julgamentos do Comitê MacCarthy, que evidenciavam, segundo Gay (2006, p. 68), “a inexorável e quase onírica ameaça da perda de nosso passado e, portanto, do nosso futuro, da presença de uma força [...] de origem humana, capaz de metamorfosear nossas vidas a partir do poder insuportável da palavra".

Riley, o cego, chama Rose por outro nome e, pela mágica desse gesto, pelo poder dessa palavra, a nova biografia de Rose se insinua, implacável; avança sobre o seu espaço de defesa, desterritorializa-a e inicia a sua colonização e metamorfose.

Poderíamos especular se Riley pertenceria a uma outra biografia de Rose; talvez aquela em que a chamariam Sal. Mas de nada, ou muito pouco, nos serviria conhecer a história de Rose. O que efetivamente vemos abduzi-la é um nome; suprema palavra, superfície essencial da personalidade. Célula mínima da identidade individual. Durante todo o seu débil contra-ataque a Riley, Rose se bate por uma causa perdida, pois a única estratégia que poderia interromper o avanço do Negro, o único escudo eficaz, seria aplicarlhe outro nome. No entanto, essa presença de espírito Rose não pôde ter. Os alicerces de sua fortaleza já vinham abalados pelo discurso de Riley sobre ela, que o senhorio acabara de lhe transmitir. E mesmo desde antes, muito antes, quando temia a presença misteriosa no porão. Sua metamorfose, desde então, desde sempre, se insinuava. E, agora, por fim, vai se completar.

Mas, quando a operação estiver terminada, quando Rose for Sal, saberemos que também em Riley se dava a metamorfose. Riley agora vê.

Bert então retornará, reconhecerá em Rose a abdução e fará o seu discurso sobre o condutor e o carro; discurso não dirigido em particular a Rose ou ao intruso, mas a ambos, 
e em que aponta para o que o distingue, como condutor do automóvel e de Rose, dos que apenas pronunciam palavras:

\begin{abstract}
Bert - Não a deixei abrandar. Ela era boa. Depois voltei. Via perfeitamente a estrada... Não havia que enganar. Com ela, não. Ela era boa. Foi comigo. Ela comigo não há que enganar. Uso as mãos. Assim. Seguro nela. Eu vou onde vou. Ela levou-me lá. Ela trouxe-me para cá.
\end{abstract}

Bert usa as mãos. Usa-as para manter firme o pacto de união, de mútua transmissão e condução entre ele e Rose: ela o leva e traz, enquanto ele a conduz; ele a leva e traz, enquanto ela o conduz.

No entanto, esse "uso as mãos" é também sinal, indício, advertência e aviso, que Bert direciona agora ao intruso, sobre sua disposição violenta.

Mas Riley não compreende que não se trata mais de palavras e se dirige a Bert para pronunciar a fórmula introdutória de uma nova biografia para Rose: "Sr. Hudd, a sua mulher...”.

Bert o elimina.

Disse antes aqui que o que os personagens de The Room procuram não é a eliminação do outro, mas sua restrição aos limites que estabelecem. Por que, então, é necessária, para Bert, essa execução?

Talvez encontremos pistas em duas outras passagens do texto. A primeira, o diálogo em que Kidd, o senhorio, externa para Rose o seu horror à presença do desconhecido no porão, e que, sintomaticamente, se inicia com Rose pondo em questão a unicidade hierárquica de Kidd:

Rose - Ouça, Sr. Kidd, o senhor é o senhorio, não é? Não há mais nenhum senhorio? Kidd - O quê? O que é que isso tem a ver? Não sei do que é que está a falar. Tenho de lhe dizer só isso. Tenho de lhe dizer. Tive um fim de semana horrível. Tem de ir lá vê-lo. Não aguento mais. Tem de ir lá vê-lo.

A segunda, a réplica irônica de Todd, o Sr. Sands, à suposição feita por sua mulher, durante a conversa com Rose, de que poderia haver dois senhorios na casa: "Ainda há de chegar o dia".

Bert sabe que a coexistência de dois senhorios é inconcebível, e compreende que o confronto com Riley é sem quartel. 
Foucault (2008, p. 184) entende que "o direito deve ser visto como um procedimento de sujeição, que ele desencadeia, e não como uma legitimidade a ser estabelecida", e lembra que "afinal, somos julgados, condenados, classificados, obrigados a desempenhar tarefas e destinados a um certo modo de viver ou morrer em função dos discursos verdadeiros que trazem consigo efeitos de poder".

Bert viu em Rose o que ela mesma não pôde ou não quis saber quando encontrou o Negro. E entendeu que se deixar Riley pronunciar a biografia que anuncia, a formulação de uma nova lei geral sobre a origem e natureza de Rose, esta o abarcará, e também ele se tornará vítima desse abdutor formidável. Daí a prontidão com que elimina a ameaça.

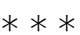

Em suas pequenas peças de câmara, Pinter conduz a atenção ao menor objeto, a partículas, a esses "elementos moleculares da sociedade" de que fala Foucault em "Soberania e disciplina". E tece variações a múltiplas vozes das formas de manifestação, nas relações entre os indivíduos, dos temas da dominação, do uso, da colonização do outro, da subjugação, da opressão, da transformação do indivíduo pela ação da palavra como condutora e agente do poder, do medo como motor dos usos desse poder pelos indivíduos etc., e assim, antecipa e inicia, a seu modo, a investigação e o método de análise proposto pelo autor de Microfísica do poder, pois, se, por um lado, é equívoco afirmar que com sua dramaturgia tivesse a intenção de fazer, como prescreve Foucault, "uma análise ascendente do poder", por outro, reconhecemos que sua matéria se confunde com os "mecanismos infinitesimais que têm uma história, um caminho, técnicas e táticas [e que] foram e ainda são investidos, colonizados, utilizados, subjugados, transformados, deslocados, desdobrados, etc." (FOUCAULT, 2008, p. 182), e se para Foucault “o problema é evitar a questão - central para o direito - da soberania e da obediência dos indivíduos que the são submetidos", Pinter já fazia, em The room, "aparecer em seu lugar o problema da dominação e da sujeição" (Idem, ibidem).

\section{BIBLIOGRAFIA CITADA:}

FOUCAULT, Michel. Soberania e disciplina. In: FOUCAULT. Microfísica do poder. São Paulo, Graal, 2008.

GAY, Ignacio Ramos. Alteridad y alienación en la dramaturgia de Harold Pinter. Revista ADE (Asociación de Diretores de Escena de España), n. 111, p. 66-76, jul.-set. 2006.

GILLEN, Francis. Humanismo e vitalidade nas peças de Harold Pinter. Sinais de cena (Revista da Associação portuguesa de críticos de teatro), Lisboa, n. 9, p. 55-72, jun. 2008.

PINTER, Harold. O quarto. Tradução de Pedro Marques, Artur Ramos, Jaime Salazar Sampaio, João Saboga e Francisco Frazão. 2. ed. Lisboa, Relógio D’Água, 2005.

VIEITES, Manuel F. Pinter y lo real: ¿deconstrucción o reconstrucción? Revista ADE - Revista de la Asociación de directores de escena de España, Madri, n. 111, p. 51-65, jul.-set. 2006. 
Abstract: In this article, the author provides an analysis of The Room, Harold Pinter's first play, from the perspective of Michel Foucault's Soberania e disciplina; Ignácio Ramos Gay's Alteridad y alienación sexual en la dramaturgia de Harold Pinter; and discusses issues raised by Francis Gillen in his essay Humanismo e vitalidade nas peças de Harold Pinter.

Keywords: Harold Pinter; Michel Foucault; Ignácio Ramos Gay; Francis Gillen. 